\title{
MUDANÇAS À VISTA NA PÓS-GRADUAÇÃO EM QUÍMICA
}

A Química no Brasil mostra um crescente avanço que se reflete quantitativamente na abertura de novos Cursos de Graduação e de Pós-Graduação. A qualidade destes Cursos é avaliada através de mecanismos próprios e específicos.

$\mathrm{Na}$ avaliação dos cursos de pós-graduação realizada pela CAPES em 98, referente ao biênio 96-97, apenas 46 cursos de pós-graduação foram reprovados. Já na avaliação realizada em 2001, relativa ao triênio 98-00, a CAPES reprovou 81 cursos de universidades brasileiras que obtiveram conceitos " 1 " e " 2 " de um total possível de 7 pontos. Esse aumento em quase $50 \%$ indica que os critérios de avaliação estão cada vez mais rigorosos. Mesmo convivendo com grandes e variadas desigualdades regionais, na área da Química nenhum programa foi desclassificado nos referidos períodos de avaliação, indicando um desempenho qualitativo notável. Porém, há necessidade de se estabelecer novos parâmetros de evolução, principalmente do ponto de vista da expansão do sistema, que ainda está aquém do desejado para a Química, devido, principalmente, ao baixo orçamento destinado às agências CNPq e CAPES, que não concederam bolsas de mestrado e doutorado aos cursos novos, aprovados em 2001-2002, que ainda não receberam bolsas. Este fato é extremamente preocupante pois, em áreas essencialmente experimentais como a Química, a dedicação exclusiva é um requisito fundamental.

A primeira avaliação continuada de 2001, referente ao triênio 2001-2003, será realizada em setembro. É necessário discutir com a comunidade os novos, e também os antigos, paradigmas desta avaliação, com uma brevidade suficiente para que os programas possam se ajustar a estas novas metas.

Neste sentido, a SBQ abriu espaço para o workshop "Um olhar sobre a pós-graduação em Química no Brasil”, na 25 Reunião Anual que foi organizado pelos Professores Jailson B. de Andrade (UFBA) e Solange Cadore (UNICAMP), convidando todos os Coordenadores de Programas de PG no Brasil, os representantes de organismos de fomento de bolsas de estudo e os avaliadores dos Programas.

Durante os debates foram levantadas diversas questões que precisam ser pensadas pela comunidade e também pelo comitê de avaliação da CAPES, especialmente no que diz respeito às bolsas disponíveis e ao futuro da PG em Química no país. Foi de entendimento geral que o processo de avaliação deve ser discutido previamente com a comunidade, divulgado com antecedência e acompanhado de relatório detalhado, informando quais os parâmetros utilizados para a classificação dos Programas nos seus diversos níveis. Na questão da classificação dos periódicos pelo sistema "Qualis", os presentes sugeriram que as revistas Journal of the Brazilian Chemical Society e Química Nova deveriam ser classificadas como de nível Internacional A. Já a Química Nova na Escola deveria ser classificada como Nacional A. Adicionalmente, solicitou-se que qualquer critério de aferição de produtividade deve incluir livros, capítulos de livros e patentes.

Alguns outros pontos importantes foram exaustivamente debatidos: i) Quais são os fatores que diferenciam os cursos 5, 6 e 7?; ii) Qual é o significado mais preciso do termo "inserção internacional"?; iii) Como comparar cursos de configuração distinta?; iv) Como valorizar livros, patentes etc no processo de avaliação?; v) O que significa a produção científica do curso? e vi) Como incluir doutores em estágio de pós-doutoramento na avaliação? Os presentes manifestaram suas opiniões sobre diversos aspectos relacionados ao futuro da PG em Química no Brasil, incluindo o financiamento das pesquisas, o papel dos Fundos Setoriais, a estagnação dos recursos destinados à pesquisa e à PG desde 1997 e o baixo valor das bolsas de estudo.

Em junho, o Coordenador da área de Química convocou o Comitê para uma reunião de trabalho visando rever a planilha "Qualis", avaliar a solicitação de cursos novos e atualizar os critérios de avaliação para o próximo triênio.

Como decisão, o Comitê modificou os pesos dos três grandes eixos que compõem a avaliação. A produção técnico-científíca dos pro- gramas passou a ter um peso de $60 \%$, baseado no total de docentes. A participação de discentes na produção do programa passou para $20 \%$, incluindo as publicações dos egressos em até um ano posterior à sua titulação. Os indicadores de eficiência na formação dos estudantes - i) número de discentes/docente total; ii) número de titulados/ docente total; iii) número de titulados/discente total; iv) 24/tempo médio de titulação no mestrado e 54/tempo médio de titulação no doutorado - passaram a ter $20 \%$ de peso.

As faixas de classificação para os periódicos inclusos no JCR permaneceram as mesmas: 0,001-0,499 (IC); 0,500-0,999 (IB); >1,00 (IA). Periódicos novos, ainda não incluídos no JCR serão classificados pelo Comitê, baseado em informações da origem do periódico. Esta planilha deverá ser analisada pelos Coordenadores dos programas que poderão sugerir modificações nos periódicos não inclusos no JCR, justificando sua importância para a área, corpo editorial e editora. Houve uma longa discussão no Comitê quanto aos periódicos Journal of the Brazilian Chemical Society (índice de impacto $=0,402$ ) e Química Nova (índice de impacto = $0,399)$, que decidiu que o $J B C S$ continua sendo considerado Internacional (IB) e a $Q N$ passa de Internacional C (IC) para IB. Foram discutidas também a inclusão da Química Nova na Escola e dos Anais da Academia Brasileira de Ciências no sistema, que passaram a ser consideradas como Nacional A (NA).

Outras formas de produção acadêmica nos indicadores dos programas foram incluídas na produção técnico-científíca: livros internacionais (IC), livros nacionais (NA), capítulos de livros internacionais (NA) e capítulos de livros nacionais (NB). Quanto às patentes, apesar do Comitê entender que se trata de um título de propriedade temporário e territorial, outorgado pelo governo, que garante aos titulares diversos direitos, decidiu-se que o depósito seria considerado como uma publicação NB e a concessão definitiva da patente (nacional ou internacional) uma publicação IA. Para não distorcer os indicadores referentes às publicações nacionais e internacionais, esses números serão somados num indicador global, separadamente.

Alguns outros possíveis parâmetros de avaliação foram levantados pelo Comitê: o fluxo de entrada e saída de docentes; as normas de credenciamento e descredenciamento dos programas; a qualificação do corpo docente com base nas bolsas de produtividade do CNPq; a superposição deste corpo docente dentro da instituição e o índice de impacto médio das publicações.

O breve relato destes dois eventos mostra claramente que o melhor caminho para se delinear um processo de avaliação participativo e afinado com a comunidade, é a discussão prévia dos critérios. Se os resultados das decisões do Comitê não foram totalmente de acordo com os anseios dos Coordenadores, grande parte dos critérios foi discutida e acatada atualizando o processo de avaliação. Porém, apenas discutir os critérios não é suficiente, temos que discutir os caminhos, as formas de aperfeiçoamento do financiamento ao sistema de PG e a prospecção de novas áreas para a Química, assim como estimular, por exemplo, os docentes a aumentarem suas publicações. Assim sendo, o Comitê pode ter relevante papel no estabelecimento destas políticas.

No que diz respeito ao estimulo à publicação nos periódicos internacionais da SBQ, mesmo com os avanços alcançados, constatamos que ainda há muito para ser feito. Neste sentido, cabe à comunidade dos químicos brasileiros avaliar a importância de contar com periódicos de qualidade, tanto em língua portuguesa como inglesa, acessíveis a um grande número de pesquisadores e estudantes da área de Química. É nossa a decisão de prestigiar essas edições e fazer com que seu reconhecimento fora do País ocorra de forma mais abrangente. 